Research Article

\title{
Factors Associated with Children Ever Born among Lower Caste Women in Some Selected Wards of Pokhara, Nepal
}

\author{
Sudan Kumar Mulmi \\ Adjunct Faculty Janapriya Multiple Campus \\ Email: mulmisudan2@gmail.com
}

Article History

Received 29 March 2018;

Revised 21 May 2018;

Accepted 30 November 2018

\begin{abstract}
Fertility is the main components of population growth. Children ever born vary in different sub groups of the same population in terms of age at marriage, age of women, literacy, occupation, contraception user and mass media exposure.The objective of this study is to find out association between children ever born and selected socio-demographic characteristics in lower caste women. A descriptive study was conducted in some selected wards of Pokhara, Nepal during April 2018. Five wards were selected randomly out of 33 wards and 187 lower caste women were selected using convenience sampling technique. The data was collected by using semi-structured interview schedule. Chi-square test was applied to find out association between children ever born and selected socio-demographic characteristics. Higher children ever born were concentrated in the age at marriage from 21 to 25 as compared to other groups of age at marriage. Practice of contraceptive use is low among lower caste people although $66.31 \%$ lower caste women were exposed to mass media. The result shows that the factors age at marriage, contraceptive use and mass media exposure were highly associated with children ever born among lower caste women under study $(\mathrm{P}<0.05)$. Education on fertility is more powerful than urban residence. Concern authorities should play vital role to increase education level among lower caste people for increasing age at marriage, contraceptive use and practice of family planning to reduce children ever born.
\end{abstract}

Keywords: Children ever born, contraception, lower caste, marriage, Nepal, women

(C) 2018 The Author. Published by JRCC, Janapriya Multiple Campus

ISSN 2362-1516

\section{Introduction}

Fertility refers to the actual production of offspring from a woman rather than the physical capability to produce. Fertility is different from fecundity which is the potential for reproduction.Fertility is the actual level of reproduction of a population based on the number of live births that occur. Fertility is normally measured in terms of woman of childbearing age defined as 15-49 years. Fertility rate is the number of offspring born per mating pair, individual or population. Many factors affect a person's fertility such as age, medical condition, genetics, environment, lifestyle and a variety of other more things. Fertility is rooted in a biological sequence of conception, gestation and birth; social and environmental factors heavily influence each stage. Children ever born are one of the main components of 
Vol. VII, 2018

population growth. Although reproduction is a biological phenomenon, levels of children ever born can be influenced by socially controlled norms and practices. Children ever born comprises information on the number of children born alive during the lifetime of the women concerned up to a specified reference date. Childrenever born is referred as to lifetime fertility. Lower castes which are also known as Dalit are those communities which are considered and treated as untouchable in traditional Nepal society. Thus they are the most backward in social, educational, economic, religious and political fields. Dalit are considered as the poorest community in Nepal.This is the reason for their poor economic condition and thus most of the lower caste people are not able to give higher education to their children. It is obvious that higher levels of education provide a higher level of information keeping children ever born under control by keeping small family size for better standard of living. Lack of education in the lower caste community results in adolescent marriage. Statistics indicate that adolescent marriages play a central role in national fertility. There arises a question that do one of the poor and educated sub group like dalit peoples have think about children ever born in their life. Do they have knowledge and desire to keep it low or not? As a result of this, the purpose of this study is to find factors those are associated with children ever born in lower caste women by studying in Pokhara.

According to census 2011, Nepal officially crossed 26.6 million figures. Over the last 10 years, Nepal added 3343081 persons to its population. The average annual growth rate of population was 2.25 percent. If it will continue in this rate, then Nepal's population will double after 50 years. Fertility in Nepal stood at 2.6 births per women in 2006-2012 (MOHP, 2012). The average family size is 4.9 persons per household (CBS, 2012). It would be important to look at the district level fertility differentials to get a better idea of the different factors contribute to the national variation of fertility. The levels and patterns of children ever born vary in various sub sectors and sub groups. A study of children ever born is important from the point of view of the implementation of family planning program because it helps us identify high fertility groups on which the program efforts can be concentrated (Clyde and whelpton, 1990). Most society viewed erroneously female children as owing responsibility and support to their marital home when married and not to their parents whereassons are, on the other hand, viewed as the ones to assists their families financially in old age as well as perpetuate family name. The drive for male children and hence high fertility is also related to religious practice (Agbim and Ikyernum, 2013). With respect to high premium on male children as compared to females, women that have only female children or who are experiencing male infant mortality are compelled to keep bearing children until the desired sons are born (Harrison, 1985). Demographic, Socio-economic and cultural factors affect fertility differentials in Nepal (Adhikari, 2010). Education, occupation and age at menarche are the most powerful factors in deciding the timing of first marriage in Nepal (Aryal, 2007). As the age at marriage increase, the number of children ever born decreases (Dahal,1989).

Pokhara Metropolitan City is the largest city of Nepal in terms of area and is the second largest city in terms of population. It is the provincial capital of province number 4 of Nepal. It is located 200 kilometers (120 miles) west of the capital Kathmandu of Nepal. According to census 2011, Population of this city stands at 413934 with males 201107(48.6\%) and females $212827(51.4 \%)$. In recent years, city has experienced a rapid increase in the number of immigrants because of its natural beauty and climate condition. This city has lower caste 
Vol. VII, 2018

people in significant number. Urban migration by Nepalese Dalit has not only provided them with social, economic and educational opportunities but also the possibility of escaping traditional caste based discrimination. However, despite making the most of opportunities provided by the city, Dalits have not been able to pursue their political agenda to the extent of other ethnic communities (Pariyar and Lovett, 2016). Despite representing about 13.1 percent of the Nepalese population (CBS, 2011), Dalit have failed to unite and clearly articulate their political agenda. Dalit continue to remain one of the most economically marginalized, politically excluded and socio-culturally oppressed communities in Nepal (Dahal et al., 2002). Although Nepal experienced a great change in the political sphere after the people's movement 2006 but change has not been able to benefit the Dalit community significantly.

Although lower caste's participation in political process and representation in government at the village, district and national level has been slowly increasing but most Dalit groups have their own traditional occupational skills like tailoring, shoemaking, iron smithy, gold smithy, fishing etc. These occupational skills are the only way to solve their hand-to-mouth problem. Dalits are not getting well fair value of their work as they deserve and thus their economic status is very poor. Most of the Dalit's living standard has not significantly increasing over years. This is the reason why they are not able to give higher and better education to their children. More than twenty Dalit caste groups from Hill and Mountain Dalit, Tarai Dalit and Newar Dalit exist in Nepal at present. The National Dalit commission of Nepal identified 22 separate cultural groups within the Dalit in 2003 (National Dalit Commission, 2003). In 2011, the number was increased to a total of 29 cultural groups within Dalit (Biswakarma, 2011). Dalits are not concentrated in any single geographic area but live throughout the country. Published statistics indicate that Dalit as a group are significantly below the national average in most development indicators such as poverty-48\%; Literacy-40\%; Chronic Childhood malnutrition-60\%, Food deficiency - 85\% and Life expectancy - 48\%years (CBS, 2011). Furthermore, the humiliating and degrading practice of untouchability is still continuing despite the country being declared 'untouchable free' by the new constitution (Bhattachan et al. 2009; Cameron, 1998 \& 2009; Lamsal, 2012). This social practice keeps most of them backward from getting well respected job and position in society.

The number of children ever born is still high in Nepal and Pokhara is not different from nation's statistics. There are so many factors responsible for high children ever born in different sub sectors and sub groups. It is not possible to achieve overall development of nation by ignoring any one sub sector or sub group. As a result, the aim of this study is to examine the associated factors of children ever born in lower caste sub group. Many studies have been done on the fertility differential among lower caste women in different study area but not in second largest populated city Pokhara metropolitan city. This study, therefore, is mainly carried out to determine and analyze the children ever born in lower castes women of some selected wards of Pokhara Metropolitan city. The major justification of the study was to provide detail and valuable information on the children ever born in lower castes peopleto advance human knowledge so that it will help to determine major associated factors which is needed as major input for decision making in planning and development programs. As the study of children ever born has importance in detecting relevant socio-demographic variables of interest for intervention so this study attempts to examine several factors affecting the children ever born among lower caste women in Pokhara, Nepal. 
Vol. VII, 2018

\section{Data and Methods}

The study population was lower castes women aged from 15 to 49 years who were permanent or temporary residents of the study area. The study area chosen was Pokhara Metropolitan City as it is the largest city and one of the most populated city of Nepal. This city has lower caste people in significant number. This study was based on primary data collected from a sample of 187 women of lower castes women.

Simple random sampling was used to select the wards of Pokhara Metropolitan City. Five wards numbering 4, 9, 12, 17 and 20 were selected randomly. Sample of 187 lower castes women were selected by rule of thumb from dalit castes distinguishes by National Dalit Commission from selected wards by using convenience sampling. Data was collected by field survey from selected wards. Convenience sampling method was used to recruit respondents living in the study area. Three eligibility criteria were used for recruiting participants. These were: Dalit castes, age from 15 to 49 years and residency, living in study area either permanently or temporarily.

Primary data has been used. Structured questionnaire was used. Interview schedule was used to get information. The data was collected by bachelor level students from field visit. After checking completeness and accuracy of the data obtained from field visit, the collected data were entered and analyzed by using statistical package for social science (SPSS) version 20.0. Descriptive statistics were conducted using frequencies. Validity and reliability has been tested by Cronbach's alpha $(\alpha=0.68)$ by using SPSS.

For statistical analysis, chi-square test was applied to examine the association between children ever born and other selected socio-demographic characteristics. The 5\% level of significance $(\mathrm{p}<0.05)$ was taken to be statistically significant.

\section{Results and Discussion}

Table 1

Respondents Classified by Castes

\begin{tabular}{lc}
\hline Castes & Number \\
\hline Biswokarma & 57 \\
Pariyar & 43 \\
Damai & 31 \\
Sarki & 30 \\
Kasai & 14 \\
Pode & 12 \\
\hline
\end{tabular}

Source: Field Survey 2017

\section{Children Ever Born by Age at Marriage}

Age at marriage is one of the main determinants of children ever born. Age at marriage is influenced by the socio-economic conditions. Table 2 shows the variation in children ever born by age at marriage. 
Vol. VII, 2018

Table 2

Respondents Classified by Age at Marriage According to Number of Children Ever Born Age at Marriage

\begin{tabular}{ccllr} 
Number of Children & $15-20$ & $21-25$ & Above25 & Total \\
0 to 1 & $19(19.2)$ & $52(52.5)$ & $28(28.3)$ & $99(100)$ \\
2 to 3 & $37(48.7)$ & $26(34.2)$ & $13(17.1)$ & \\
4 to 5 & $8(66.7)$ & $3(25)$ & $1(8.3)$ & $16(100)$ \\
Total & $64(34.2)$ & $81(43.32)$ & $42(22.5)$ & 187 \\
\hline
\end{tabular}

Note: Chi-square value $=22.724$ with $\mathrm{p}<0.01$

Source: Field Survey 2017

Table 2 demonstrates that out of 187 respondents, 64(34.2\%) women were married in the age ranges from 15 to $20,81(43.3 \%$ ) women were married in the age ranges from 21 to 25 and $42(22.5 \%)$ women were married in the age above 25 years. Out of 99 respondents having children ever born ranges from 0 to $1,19.19$ percent are in the age group of 15-20,52.53 percent are in the age group of 21-25 and 28.28 percent are in the age group above 25 . Out of 76 respondents having children ever born ranges from 2 to $3,48.7$ percent are in the age group 15-20, 34.2 percent are in the age group of 21-25 and 17.11 percent are in the age group above 25. Similarly, out of 12 respondents having children ever born ranges from 4 to $5,66.7$ percent are in the age group 15-20, 25 percent are in the age group 21-25 and 8.33 percent are in the age group above 25. Chi-square test is used to test association between children ever born and age at the marriage. The p-value is 0.00014 . As p-value is less than 5 percent so study shows that there is significant association between children ever born and age at marriage in lower caste families.

\section{Children Ever Born by Age of Women}

Children ever born are affected by age of mother. Age of mother is another important determinates of children ever born. Table 3 shows the variation in children ever born by age of women.

Table 3

Respondents Classified by Age of Women According to Number of Children Ever Born

\begin{tabular}{cllll}
\hline \multicolumn{5}{c}{ Age of Married Women } \\
\hline Number of Children & $15-25$ & $26-35$ & $36-49$ & Total \\
0 to 1 & $31(31.3)$ & $42(42.4)$ & $26(26.3)$ & $99(100)$ \\
2 to 3 & $17(22.4)$ & $35(46.1)$ & $24(31.6)$ & $76(100)$ \\
4 to 5 & $1(8.3)$ & $4(33.3)$ & $7(58.3)$ & $12(100)$ \\
Total & $49(26.2)$ & $81(43.3)$ & $57(30.5)$ & 187
\end{tabular}

Source: Field Survey, 2017 


\section{Vol. VII, 2018}

Table 3 demonstrates that out of 187 respondents, 49(26.2\%) women are in the age group 15$25,81(43.3 \%)$ women are in the age group 26-35 and 57(30.5\%) women are in the age group 36-49. Higher children ever born are concentrated in the age group 36-49. Chi-square test is used to test the association between children ever born and age of married women. The pvalue is 0.1378 . As p-value is greater than 5 percent so study shows that there is no significant association between children ever born and age of married women in lower caste families.

\section{Children Ever Born by Lite racy}

Literacy is the ability to read and write. Literacy of women has great influence in children ever born. Literate women become more knowledgeable about family planning and contraceptive use method. This helps directly in reducing children ever born. Table 4 shows the variation of children ever born by literacy.

Table 4

Respondents Classified by Literacy According to Number of Children Ever Born Level of Literacy

\begin{tabular}{clll}
\hline Number of Children & Literate & Illiterate & Total \\
0 to 1 & $57(57.8)$ & $42(42.4)$ & $99(100)$ \\
2 to 3 & $42(55.2)$ & $34(44.7)$ & $76(100)$ \\
4 to 5 & $3(25.0)$ & $9(75)$ & $12(100)$ \\
Total & $102(54.5)$ & $85(45.5)$ & 187 \\
\hline
\end{tabular}

Source: Field Survey 2017

Table 4 demonstrates that out of 187 respondents, 102(54.6\%) women were literate and $85(45.5 \%)$ women were illiterate. Out of 99respondents, $57(57.6 \%)$ respondents have children ever born from 0 to 1 . Out of 76 respondents, 42(55.3\%) literate respondents and 34(44.74\%) illiterate respondents have children ever born from 2 to 3 . Similarly, out of 12 respondents, $3(25 \%)$ literate and $9(75 \%)$ illiterate respondents have children ever born from 4 to 5 . Out of 187 respondents, 102(54.6\%) respondents were literate and 84(45.5\%) respondents were illiterate. Chi-square test is used to test the association between children ever born and literacy status. The p-value is 0.09989 . As $\mathrm{p}$-value is greater than 5 percent so study shows that there is no significant association between children ever born and literacy status in lower caste families.

\section{Children Ever Born by Occupation}

Occupation is one of the important determinants of children ever born. Employment might reduce women's hazard of marriage and pregnancy. Women having occupation are most likely to postpone first birth. For this study, respondents other than household work and dependent are considered as working. Table 5 shows the variation in children ever born by occupation status. 
Vol. VII, 2018

Table 5

Respondents Classified by Occupation according to Number of Children Ever Born

\begin{tabular}{llll}
\hline & \multicolumn{3}{c}{ Occupation Status } \\
\hline Number of children & Working & Non-working & Total \\
0 to 1 & $64(64.7)$ & $35(35.4)$ & $99(100)$ \\
2 to 3 & $47(61.8)$ & $29(38.2)$ & $76(100)$ \\
4 to 5 & $5(41.7)$ & $7(58.3)$ & $12(100)$ \\
Total & $116(62.0)$ & $71(37.9)$ & 187 \\
\hline
\end{tabular}

Source: Field Survey 2017

Table 5 demonstrates that out of 187 respondents, $116(62.03 \%)$ respondents were working and $71(37.9 \%)$ respondents were non-working. Majority of lower caste respondents are working respondent. Out of 99 respondents, 64 (64.7\%) working respondents and 35(35.4\%) non-working respondents have children ever born ranges from 0 to 1 . Out of 76 respondents, $47(61.8 \%)$ working respondents and 29 (38.2\%) non-working respondents have children ever born ranges from 2 to 3 . Similarly, out of 12 respondents, 5(41.7\%) working respondents and $7(58.3 \%)$ non-working respondent have children ever born ranges from 4 to 5 . Chi-square test is used to test association between children ever born and occupation status. The p-value is 0.3009. As p-value is greater than 5 percent so study shows that there is no significant association between children ever born and occupation status in lower caste families.

\section{Children Ever Born by Contraception}

Contraceptive use allows women to prevent from fertilization. It helps couples to achieve their desired family size by stopping unwanted births. Contraceptive use helps to stop giving birth or to increase the birth interval. It is expected to have low children ever born for those who use contraception

Table 6

Respondents Classified by Use of Contraceptive According to Number of Children Ever Born

\begin{tabular}{llll}
\hline & \multicolumn{3}{c}{ Use of Contraceptive } \\
\hline Number of Children & User & Non-user & Total \\
0 to 1 & $58(58.6)$ & $41(41.4)$ & $99(100)$ \\
2 to 3 & $27(35.5)$ & $49(64.5)$ & $76(100)$ \\
4 to 5 & $2(16.7)$ & $10(83.3)$ & $12(100)$ \\
Total & $87(46.5)$ & $100(53.5)$ & 187 \\
\hline
\end{tabular}

Note: Chi-square value $=13.7838$ with $\mathrm{p}<0.01$

Source: Field Survey 2017

Table 6 demonstrates that out of 187 respondents, 87(46.5\%) respondents were users of contraception and 100(53.5\%) were non-users of contraception. Out of 99 respondents, 58 $(58.59 \%)$ contraception users and $41(41.41 \%)$ contraception non-users have children ever born ranges from 0 to 1 . Out of 76 respondents, 27(35.5\%) contraception users and 49(64.5\%) contraception non-users have children ever born ranges from 2 to 3. Similarly, out of 12 respondents, 2(16.7\%) contraception users and 10(83.3\%) contraception non-users have child ever born ranges from 4 to 5 . Chi-square test is used to test the association between children ever born and contraception users. 
Vol. VII, 2018

\section{Children Ever Born by Mass Media Exposure}

Mass media can affect fertility in women. It is expected to have low fertility level for those women who are exposed to mass media as they are likely to use contraception than the nonexposed women. Table 7shows the variation in children ever born by mass media exposure.

Table 7

Respondents Classified by Mass Media Exposure According to Number of Children Ever Born

\begin{tabular}{llll}
\hline & \multicolumn{3}{c}{ Mass Media Exposure } \\
\hline Number of children & Yes & No & Total \\
0 to 1 & $64(64.7)$ & $35(35.4)$ & $99(100)$ \\
2 to 3 & $57(75.0)$ & $19(25.0)$ & $76(100)$ \\
4 to 5 & $3(25.0)$ & $9(75.0)$ & $12(100)$ \\
Total & $124(66.3)$ & $63(33.7)$ & 187 \\
\hline
\end{tabular}

Note: Chi-square value $=11.8584$ with $\mathrm{p}<0.01$

Source: Field Survey 2017

Table 7 demonstrates that out of 187 respondents, 124(66.3\%) respondents were exposed to mass media and 63(33.7\%) respondents are not exposed to mass media. Out of 99 respondents, 64(64.7\%) exposed respondents and 35(35.4\%) non-exposed respondents have children ever born ranges from 0 to 1 . Out of 76 respondents, 57(75.0\%) exposed respondents and $19(25.0 \%)$ non-exposed respondents have children ever born from 2 to 3 . Similarly, out of 12 respondents, 3(25\%) exposed respondents and 9(75\%) non-exposed respondents have children ever born ranges from 4 to 5 . Chi-square test is used to test the association between children ever born and mass media exposure. The p-value is 0.00266 . As p-value is less than 5 present so there is significant association between children ever born and mass media exposure in lower caste families.

This study examines the socio-demographic variables that are associated with children ever born in lower caste women as distinguishes by National Dalit Commission of some selected wards of Pokhara Metropolitan City. The discussion on finding was based on results obtained from chi-square test. Age at marriage in lower caste women found significant with children ever born in present study since p-value is less than 0.05 (0.00014). Similar result was found in a study conducted in Bangladesh by Kabir et al. (2001). This could be because of the fact that most of the lower caste women participated in this study was married at lower age. A lower age at marriage provides a long reproduction span and thus may results in higher children ever born. Rise in the age of marriage can reduce children ever born. The present study showed that children ever born in lower caste women are not significantly associated with the age of mother since p-value is greater than 0.05(0.1378). This result was consistent with the study conducted by Gautam and Paudel (2014) in Lamachaur of Kaski of Nepal.

Surprisingly, literacy had no significant association with children ever born of lower caste women since $\mathrm{p}$-value is 0.09989 ( $\mathrm{P}>0.05)$. This result was inconsistent with the results of other research. Literacy in women reduces the fertility level (Susuman, Lougue and Battala, 2014). The desire to limit child bearing is more apparent at higher levels of education than at lower levels (MOHP, 2011). This may be due to the fact that education in lower caste women was not much higher though they were living in urban region. In present study, occupation 
Vol. VII, 2018

status of lower caste women was not statistically associated with children ever born in lower cast women since p-value is $0.3009(\mathrm{P}>0.05)$. The result was supported by Gautam and Paudel(2014). The previous research suggests that occupation has significant association with children ever born (Begall and Mills, 2013). But present study has no evidence of a statistically significant in lower caste women. The present study showed that working respondents have higher children ever born than non-working respondents. This could be because of the fact that most of the lower caste people are migrated from rural area and had to work to solve their hand-to-mouth problem. Husbands of nonworking women might be abroad.

The present study showed that 46.5 percent respondents are user of contraception and 53.48 percent respondents are non-user of contraceptive. The result also showed that non-user of contraception had higher children ever born. Children ever born are significantly associated with the contraceptive use. This result was similar with the result of Morgan and Niraula (1995). This may be due to the possibility of less educated lower caste women were not practicing the use of contraception in real life scenario. In present study, 66.3 percent respondents were exposed to mass media and 33.7 percent respondents were non-exposed to mass media. The study showed that children ever born was significantly associated with mass media exposure since p-value is $0.00266(\mathrm{P}<0.05)$. This result is consistent with many previous studies that showed mass media exposure reduces the children ever born in women (Cheng, 2011; Bankole, Rodriguez and Westoff, 1996). These are a number of reasons that mass media exposure reduces the children ever born. Mass media provides knowledge of contraceptive use and family planning method. Mass media provides benefits of small family size. No matter which fertility metric is measured, the knowledge of contraceptive use and family planning will reduce children ever born to some extent. This will also be applicable for lower caste women too.

\section{Conclusion}

The major finding of present study is that significant factors of children ever born in lower caste women in Pokhara, Nepal are age at marriage, contraceptive use and mass media exposure. As age at marriage is earlier for most of the respondents so they have a longer reproductive lifespan. This may result in higher number of children ever born. Rise in the age of marriage may reduce children ever born in lower caste women. Children ever born is highly concentrated in non-user of contraceptive. This may be due to the possibility of less educated lower caste women were no practicing the use of contraception in real life scenario. Respondents who do not practicing the use contraceptive have more chances to get pregnant and this results in higher childrenever born. Low children ever born was concentrated to those respondents who had exposure to mass media. This is because the respondents who have exposure to mass media had more knowledge of contraceptive use and family planning method. Mass media provides them the benefits of small family size in future's better standard life.

\section{Acknowledgements}

Author would like to thank all the participants for their valuable information and B.Sc. III as well as BBS I year students for helping in data collection. The author is greatly indebted to 
Vol. VII, 2018

Prof. Dr. Vikash Kumar K.C. for his guidance.

\section{References}

Adhikari, (R..2010). Demographic, Socio-economic and cultural factors affecting fertility differential in Nepal. BMC Pregnancy and Childbirth, 10, 19.

Agbim, K.C., \&Ikyernum, J. (2013). Fertility and fertility determinants: A nexus for understanding the need to manage the fertility of women in Awka town, Anambra state, Nigeria. The International Journal of Engineering and Science, 2(8), 48-56.

Aryal, T.R. (2007). Age at first marriage in Nepal: Differentials and determinants. Journal of Biosocial Science, 39(5), 693-706.

Bankole, A., Rodriguez, G., \&Westoff C.F. (1996). Mass media massages and reproduction behavior in Nigeria. Journal of Biosocial Science, 28(2), 227-239.

Begall, K. \& Mills, M.C. (2013). The influence of educational field, occupation and occupational sex segregation of fertility in Netherland.European Sociological Review, 29(4), 720-742.

Cameron, M. (2009), Untouchable healing: A dalitayurvedic doctor from Nepal suffers his country's ills.Medical Anthropology: Cross - Cultural Studies in Health and Illness, 28(3), 235-267.

Central Bureau of Statistic (CBS) [Nepal]. National Population and Housing Census 201. Kathmandu, Nepal.

Cheng, K.W. (2011). The effect of contraceptive knowledge on fertility. The role of mass media and social networks. Journal of Family and Economic Issue, 32(2), 257-267.

Clyde, V.K., \&whelpton, P.K. (1946). Social and Psychological Factors affecting fertility. The Milbank memorial Fund Quarterly, 24(1), 49-93.

Dahal, D.R. (1989). Demand aspect of fertility and family planning in Nepal. South Asia Study on Population Program and Strategies. Kathmandu. UNFPA, 73-79.

Gautam, K.R. \&Paudel, P. (2014). Fertility differential among lower cast in Lamachour VDC, Kaski. Janapriya Journal of Interdisciplinary studies, 3, 47-53.

Harrison, K.A. (1985). Child bearing, health and social priorities: A survey of 22774 consecutive hospital birthin Zaria, Northen Nigeria. British Journal of Ubstetrics and Gynecology, 5, 1-19.

Kabir, A., Jahan, G. \& Jahan, R. (2001). Female Age at Marriage as a Determinant of Fertility. Journal of Medical Sciences, 1, 372-376.

Lamsal, H.B. (2012). Role of dalit civil society against untouchability: Challenges and Prospects. Nepal Journal of Social Science and Policy, 2(1), 76-84.

Ministry of Health and Population (MOHP) [Nepal], New ERA, and ICF International Inc. 2012.Nepal Demographic and Health Survey 2011. Kathmandu, Nepal.

Morgan, S.P., \&Niraula, B.B. (1995). Gender inequality and fertility in two Nepali villages.Population and Development Review, 21(3), 541-561.

Pariyar, B., \& Lovett, J.C. (2016). Dalit identity in urban Pokhara, Nepal. Geoforum, 75, 134147.

Susuman, A.S., Lougue, S. \&Bhattala, M. (2014). Female literacy, fertility decline and life expectancy in Kerala, India: An analysis from census of India 2011. Journal of Asian and African Studies, 51(1), 3242. 